\title{
A RESTRIÇÃO DA LIBERDADE DE CULTO NA PANDEMIA DE COVID-19
}

\author{
Gustavo Henrique Maia Garcia ${ }^{1}$ \\ Paula Senra de Oliveira Amaral ${ }^{2}$
}

\section{RESUMO}

$\mathrm{O}$ artigo analisa a possibilidade e a intensidade de eventuais restrições à realização de cultos durante a pandemia de covid-19, cuja principal forma de propagação se dá pela aglomeração humana. Utiliza-se o método hipotético-dedutivo para verificar a consistência dos posicionamentos jurisprudenciais brasileiros sobre o assunto, comparando com experiências vividas por outros países.

Palavras-chave: Direitos Fundamentais. Liberdade religiosa. Aglomeração. Pandemia. Covid-19.

\section{THE RESTRICTION OF THE FREEDOM OF WORSHIP DURING COVID-19 PANDEMIC}

\begin{abstract}
The article analyses the possibility and intensity of possible restrictions on the holding of religious cults during the covid-19 pandemic, whose main form of propagation is through human agglomeration. The hypothetical-deductive method is used to verify the consistency of the Brazilian Courts understanding on the subject, comparing it with experiences in other countries.
\end{abstract}

Keywords: Fundamental Rights. Freedom of worship. Crowding. Pandemic. Covid-19.

\section{INTRODUÇÃO}

A pandemia de Covid-19 não foi a primeira e, provavelmente, não será a última vivida pela humanidade. Porém, não há precedentes para tamanho e amplitude de seu impacto, que foi multiplicado por um mundo altamente conectado, com intenso fluxo de pessoas e interdependência econômica. Ao mesmo tempo, o vírus encontrou uma sociedade global navegando em um oceano de informações, cujos excesso e velocidade contribuíram

\footnotetext{
1 Mestrando em Direito pela Universidade de Itaúna-MG. Especialista em Direito Constitucional pela Universidade Anhanguera-Uniderp. Bacharel em Direito pela Universidade Federal de Juiz de Fora. Advogado. E-mail: gustavohmgarcia@gmail.com. Orcid: https://orcid.org/0000-0003-0485-863X.

${ }^{2}$ Mestranda em Direito pela Universidade de Itaúna-MG. Especialista em Direito Internacional e Direitos Humanos pelo IEC PUC-Minas. Bacharel em Direito pela PUC Minas. Advogada. E-mail: paulasenra.adv@gmail.com. Orcid: https://orcid.org/0000-0003-4140-977X.
} 
para a divergência sobre a doença, contribuindo para o aprendizado sobre o vírus, mas também provocando o caos no combate à sua proliferação.

Com a progressiva aprendizagem sobre a doença, foram várias as recomendações de autoridades de saúde em diferentes lugares do mundo, com um fechamento quase total na fase inicial e sucessivas aberturas e fechamentos de escolas, comércios e outros estabelecimentos. Desde o momento em que se descobriram fortes indícios de que a Covid-19 possuía alta transmissão por via aérea, tornou-se prioritário reduzir a concentração de pessoas em locais fechados, pouco ventilados, a não ser que fosse estritamente necessário, como nos próprios hospitais.

Ao lado de escolas e estabelecimentos não essenciais, os templos religiosos também foram logo solicitados a não promover a aglomeração de pessoas, sendo esta um relevante vetor de contágio para comunidades inteiras, como se verificou desde logo na Coréia do Sul. O fechamento ou a restrição de funcionamento compulsórios desses templos importa em relevante intervenção no exercício da liberdade religiosa, o que exige a revisitação de questões relativas à liberdade de culto, que se mostraram controversas mesmo na mais alta corte brasileira.

Na Ação de Descumprimento de Preceito Fundamental no 811 (BRASIL, 2021-B), julgada pelo Supremo Tribunal Federal em abril do ano de 2021, por maioria de nove votos a dois, a corte decidiu ser constitucional norma estadual que impõe restrições às atividades religiosas coletivas, baseando-se em critérios técnicos relativos ao risco ambiental de contágio pela Covid-19. A decisão, também adotada por outros países, seguiu a orientação das principais autoridades de saúde mundiais, e foi tomada no momento mais crítico, até então, da pandemia no Brasil, no dia em que o país registrou o maior número de mortes em um único dia: 4249 (BRASIL, 2021-A).

Por outro lado, a pandemia já completa mais de vinte meses em um cenário de distribuição desigual de vacinas entre os países e com a crescente recusa de parte da população em se imunizar. Esse cenário, somado ao surgimento de novas variantes do coronavírus, traz incertezas quanto ao futuro do modo de vida humano, devendo haver constante reavaliação das medidas sanitárias e da restrição de direitos, como é o caso da suspensão da celebração de cultos religiosos.

As discussões acerca da liberdade religiosa têm uma longa história através dos séculos, em razão da grande capacidade de mobilização social que inspira e dos não raros 
atritos de instituições religiosas com o poder político. Já na Roma antiga, primeiro grande império multicultural, era possível verificar conflitos entre os fiéis e o Estado, mas também foram desenvolvidas ferramentas de conciliação entre as diferentes crenças.

Como fenômeno social complexo, a celebração de cultos é um elemento importante para grande parte das religiões, pois é neles que as comunidades reproduzem os ritos e preservam a essência de seu modo de vida tradicional. Embora muitos líderes religiosos concordem que é preciso preservar a vida dos fiéis em primeiro lugar, existe por parte de outros uma forte pressão para a reabertura dos templos, mesmo nos momentos mais graves da pandemia, fenômeno que não é exclusivo das instituições religiosas, sendo abraçado por boa parte do mercado e da classe política.

Portanto, é preciso esclarecer quais são as restrições constitucionalmente admitidas que o Estado pode opor ao exercício da liberdade de culto religioso, em um cenário de um futuro incerto, mas certamente impactado por novos padrões sanitários exigidos para toda a sociedade. Assim, pergunta-se até que ponto, e em que condições, pode o Poder Público exigir o fechamento compulsório de templos ou seu funcionamento com restrição de público e horários, a partir da análise da decisão proferida na ADPF $\mathrm{n}^{\circ} 811$ e de experiências negacionistas vividas em outros países.

Na primeira seção, denominada “A Covid-19 e o problema das aglomerações", aborda-se a importância das medidas de prevenção contra a Covid-19, sobretudo do distanciamento social, trazendo exemplos de manifestações religiosas que atuaram contra as medidas sanitárias de prevenção da doença, e também de países que conseguiram bons resultados a partir do controle profilático, somente com a prevenção. Dessa forma, pretendese demonstrar como o contágio do vírus tem uma importante relação com a aglomeração de pessoas, e como a forma de desenvolvimento de cultos religiosos têm uma especial importância no combate à pandemia.

Na segunda seção, intitulada “A desinformação como catalisadora da pandemia”, são exploradas questões relativas à produção e à disseminação de informações sobre a doença e as medidas de prevenção. Pretende-se demonstrar como a transmissão de informação de credibilidade é uma arma importante de combate da pandemia, enquanto campanhas de desinformação podem ser desastrosas, e qual é a importância das instituições religiosas nesse processo. 
Na terceira e última seção, "A liberdade religiosa e a liberdade de culto", é trazido à discussão o posicionamento mais recente do Supremo Tribunal Federal sobre a possibilidade de restrição total de cultos religiosos por determinação de Estados e Municípios durante a pandemia de Covid-19. Procura-se verificar se tal proibição atenta contra a liberdade religiosa, considerando que o surto ainda não tem previsão de término, e que novas variantes ou novas doenças de transmissão respiratória podem surgir e levantar as mesmas questões ora discutidas.

\section{A COVID-19 E O PROBLEMA DAS AGLOMERAÇÕES}

No último dia do ano de 2019, quando a OMS - Organização Mundial da Saúde foi alertada sobre a descoberta de uma nova doença respiratória pelas autoridades médicas de Wuhan, na China, o mundo não tinha ideia do que aquilo poderia se tornar, embora os especialistas em infectologia saibam que de tempos em tempos alguma pandemia irá surgir, como foi a peste bubônica no século XIV, a de veríola entre 1896 e 1980, a gripe espanhola entre 1918 e 1920, e mais recentemente com a influenza H1N1 em 2009 (IAMARINO; LOPES, 2020). Outros novos vírus, também da família dos coronavírus, com potencial para se transformarem em epidemias foram identificados: em 2003, o SARS-CoV-1 e no ano de 2012, o MERS-CoV.

Por sua vez, o novo vírus causador da Covid-19, o SARS-CoV-2, demonstrou muito maior transmissibilidade, rapidamente atingindo todo o mundo, crescendo sob progressão geométrica. Logo percebeu-se que a maior virtude desse vírus era a grande capacidade de transmissão pelo ar, quando uma pessoa saudável respira o ar contaminado daquele que foi infectado (IAMARINO, LOPES, 2020, p. 41).

Além da alta transmissibilidade, algumas pessoas ainda estão sujeitas a desenvolver a forma grave da doença, podendo levar a sequelas graves ou à morte, riscos inadmissíveis no modelo de Estado Democrático de Direito adotado pelo Brasil, como deixa claro o art. 196 da Constituição Federal: "A saúde é direito de todos e dever do Estado, garantido mediante políticas sociais e econômicas que visem à redução do risco de doença e de outros agravos e ao acesso universal e igualitário às ações e serviços para sua promoção, proteção e recuperação". No ordenamento constitucional brasileiro, no art. 200, II, ainda é prevista a 
competência do SUS - Sistema Único de Saúde para “executar as ações de vigilância sanitária e epidemiológica" (BRASIL, 1988).

A coordenação de ações de saúde pelo Estado de forma unificada é uma característica marcante do constitucionalismo social (CANOTILHO, 1993), e é em uma grave pandemia que um sistema público de saúde será mais exigido. Com base nas análises realizadas pelos primeiros dados coletados em Wuhan, foram projetados cenários catastróficos para qualquer lugar do mundo em que o SARS-CoV-2 desembarcasse e infectasse livremente a população. Foi o que aconteceu logo na Itália, um país com boa estrutura hospitalar, mas que ainda assim não teve condições de atender à gigantesca demanda gerada pela Covid-19.

Por outro lado, alguns países que já haviam recentemente sofrido com surtos de novas doenças, como as causadas pela SARS-CoV-1 e pelo MERS-CoV, já haviam estudado e desenvolvido protocolos sanitários para conter epidemias futuras, já que havia uma probabilidade muito alta de novas surgirem. Taiwan, por exemplo, cuja política de contenção ao surto de SARS de 2002 foi muito criticada à época, dessa vez mostrou-se muito mais preparado, sendo um dos países que melhor protegeram suas populações, um país de mais de 23 milhões de habitantes, com somente 15 mortes confirmadas até o dia 21 de maio de 2021, momento em que novas variantes mais contagiosas elevaram substancialmente esse número, embora tenha conseguido controlar posteriormente (OUR WORLD IN DATA, 2021).

O sucesso de Taiwan é atribuído à adoção eficiente de um conjunto de políticas de controle baseadas em casos e baseadas na população. As primeiras se voltam para a identificação e rastreamento de infectados, determinando o seu isolamento para que não transmita para outras pessoas, enquanto a segunda trata daquelas medidas preventivas de responsabilidade de toda a população, como higiene pessoal, uso de máscaras e distanciamento social (TA-CHOU et. al, 2021).

Outro país que obteve bons resultados de controle no início da pandemia foi a Coréia do Sul, que também reuniu a experiência de combate à SARS-CoV-1 e ao MERS-CoV (WALLACE, 2020), agindo rapidamente no início do surto, principalmente em razão da proximidade e intensidade do fluxo de pessoas que mantém com a China. O Vietnã e a Coréia do Sul obtiveram resultados muito bons durante o ano de 2020, agindo rapidamente, sempre objetivando o rastreamento de casos e o isolamento social (UCHOA, 2021). 
Por outro lado, mesmo empregando custosas estratégias de testagem em massa, a Coréia do Sul encontrou resistência por parte da população, incentivada por campanhas de desinformação. O país verificou surtos provocados por celebrações religiosas de igrejas que insistiram em desacreditar o vírus, criando teorias conspiratórias para justificar as pretensas restrições propostas pelo governo (BICKER, 2020). Também no início da pandemia, em março de 2020, o Centro de Controle e Prevenção de Doenças dos Estados Unidos da América identificou que, após o culto de uma igreja no estado do Arkansas, 38\% do total de 92 participantes foram infectados pelo coronavírus, o que provocou a morte de três deles (FERNANDES, 2020).

No Brasil, a pandemia foi marcada pela ausência de uma coordenação nacional em razão de escolhas realizadas na esfera federal, cabendo a estados e municípios realizar ações de enfrentamento à Covid-19, poder-dever assegurado pela decisão proferida na Ação Direta de Inconstitucionalidade $n^{\circ}$ 6341/DF (STF, 2020). Porém, a falta de uma política unificada, principalmente quanto ao rastreio de casos e conscientização sobre o distanciamento social, trouxe resultados terríveis (CASTRO et. al, 2021), com o descontrole da transmissão e o registro acumulado de quase seiscentas mil mortes registradas até setembro de 2021 (BRASIL, 2021-D).

Dentre todas as medidas conhecidas de contenção do vírus, o distanciamento social é aquela mais simples, pois sem compartilhar o ar ingerido por pessoas próximas e sem tocar superfícies contaminadas, como corrimãos e botões de elevador, torna-se impossível a transmissão. Nesse sentido, foi recomendado às autoridades estatais que se determinasse o fechamento de todo evento que provoque naturalmente a concentração de pessoas, não só em templos religiosos, mas também em shows, palestras, escolas e bares. O impacto econômico e social não tem precedentes, porém, enquanto ainda não é possível imunizar toda a população com a utilização de vacinas, tais medidas mostram-se adequadas para proteger o bem maior que é a vida.

É nesse contexto que surge a discussão acerca da possibilidade do Poder Público, seja ele em esfera federal, estadual ou municipal, determinar o fechamento temporário de templos religiosos para evitar que eles se tornem grandes vetores de transmissão do vírus. A partir da decisão do Supremo Tribunal Federal na ADI n 6341/DF, em abril de 2020 (STF, 2020), diante da inércia do governo federal em traçar planos e políticas de controle para o país, os diversos outros entes federados traçaram seus próprios planos, cada um com 
diferentes concepções e estratégias, desde a previsão de multa para quem se negasse a utilizar máscaras em locais públicos, até a decretação de lockdown, com o fechamento de todos os estabelecimentos considerados não essenciais.

Muitos desses atos normativos foram impugnados judicialmente, sendo as mais notáveis a Ação de Descumprimento de Preceito Fundamental - ADPF no 701 (STF, 2021-C), proposta pela Associação Nacional de Juristas Evangélicos (ANAJURE), e a ADPF $\mathrm{n}^{\circ} 811$ (STF, 2021-B), proposta pelo Partido Social Democrático. No primeiro processo, o Ministro Relator Kassio Nunes Marques concedeu liminar impedindo que estados, municípios e Distrito Federal possam impedir cultos, estabelecendo também medidas sanitárias mínimas a serem cumpridas pelas instituições religiosas. Dois dias depois, o Ministro Gilmar Mendes, relator do segundo processo, indeferiu o pedido de liminar, afirmando a possibilidade de restrição total de eventos religiosos em decorrência da pandemia, caso a medida se demonstre necessária.

Para unificar o entendimento da Corte, foi então dado seguimento ao julgamento da ADPF $n^{\circ} 811$, na qual o plenário do STF julgou, por 9 votos a favor e 2 contra, constitucional a restrição, inclusive total, à realização de eventos religiosos, em razão do grave momento pandêmico vivido pelo país, enquanto diversos hospitais estavam em colapso e pessoas morriam à espera de vagas de UTI - Unidade de Tratamento Intensivo (PRUDENCIANO, 2021).

Desde o início da pandemia, houve uma expansão muito grande do número de leitos de UTI no país (SOARES; FERREIRA, 2020), já que um dos principais problemas da Covid19 é o extenso prazo de internação de pacientes graves, comprometendo a estrutura hospitalar se o número de casos for muito grande, gerando uma carência de leitos que prejudica também pacientes que precisam ser internados por outras razões. Com efeito, a disponibilidade de leitos passou a ser um dos principais fatores para analisar o controle ou descontrole da pandemia em cada localidade, ainda que até um em cada três pacientes com Covid-19 internados em UTI não sobrevivam (EPIMED MONITOR, 2021).

Após aquele grave momento vivido pelo país entre março e abril de 2021, o avanço da vacinação, principalmente para as pessoas mais vulneráveis, promoveu uma grande redução de mortes diárias, gerando otimismo, de forma que os próprios governantes foram progressivamente reduzindo as restrições. Com a redução de casos graves e de internações em UTI, o registro de maiores índices ociosidade passou a ser interpretado como controle da 
pandemia, justificando a abertura de eventos maiores como shows e jogos de futebol com torcida, ainda que reduzida.

Contudo, há fortes evidências de que as principais vacinas aplicadas no Brasil, embora tenham boa eficácia global para reduzir a circulação do vírus e prevenir internações e mortes por Covid-19, não impedem a transmissão, e sua eficácia tende a diminuir quanto maior é a idade do paciente (CERQUEIRA-SILVA et. al., 2021). Atualmente, países que primeiro avançaram na vacinação de suas populações, como Israel e Estados Unidos da América, como se pode verificar dos gráficos gerados pela plataforma Our World in Data (2021), mostram que as novas variantes do coronavírus significam um desafio muito maior para a humanidade, sobretudo diante da resistência de parcelas da população em se vacinar.

Diferentes variantes do vírus, com distintas mutações, prevalecem porque são mais infecciosas, como a Delta, surgida na Índia, exigindo uma maior cobertura vacinal para frear a pandemia, o que deve ser feito em escala global. Seu potencial de infecção foi demonstrado ao conseguir quebrar os sistemas de países que anteriormente obtiveram sucesso com políticas de controle baseadas em casos e em população, como Taiwan, Austrália e Coréia do Sul. Mais do que nunca, está claro que a Covid-19 é um problema de todos, e sem a colaboração entre toda a comunidade internacional e entre todos os setores da sociedade, o desafio de conte-la torna-se muito mais difícil.

\section{A DESINFORMAÇÃO COMO CATALISADORA DA PANDEMIA}

Diferente do que ocorreu na pandemia de influenza entre 1918 e 1920, hoje a humanidade conta com diversas ferramentas científicas para identificar e entender microrganismos capazes de provocar doenças contagiosas, a ponto de desenvolver uma série de vacinas em tempo recorde, em diversos centros de pesquisa espalhados pelo mundo. Além disso, o avanço dos meios de comunicação, sobretudo os baseados na internet, permite trocas instantâneas de informação entre profissionais de diversas áreas do conhecimento, sendo capazes de levar a todos informações importantes sobre a prevenção e o tratamento de doenças contagiosas.

Por outro lado, a grande velocidade da circulação de dados e os diversos conflitos de interesse de setores da sociedade deu margem para a potencialização de campanhas de desinformação, circulando boatos, notícias imprecisas ou mesmo autênticas mentiras sobre 
assuntos pontuais, o que se tem denominado de fake news. A propagação consciente de desinformação é conhecida pelo menos desde o antigo Império Romano (MARQUÉS, 2019), e já atuava durante a pandemia de Influenza do início do século XX, quando disputas políticas e o negacionismo contribuíram para a disseminação da doença e a multiplicação das mortes (SCHWARCZ; STARLING, 2020).

Por sua natureza, as religiões também têm, cada qual, a sua maneira de explicar o mundo e a realidade, oferecendo respostas com base em uma verdade revelada, muitas vezes com base na interpretação de textos sagrados. Foi dessa forma que o líder de uma igreja sulcoreana, anteriormente mencionada, afirmou que se trata de um vírus terrorista com objetivo de destruir a sua igreja (BICKER, 2020). Os contextos que levam grupos sociais a criar e difundir informações falsas sobre a doença são de difícil explicação e demandam um estudo muito mais complexo, considerando interesses econômicos e político-ideológicos, com motivações que variam desde o impulsionamento da venda de fármacos ineficientes até a desmoralização do regime político de outros países.

É importante ressaltar o poder de influência que líderes religiosos têm sobre seus fiéis e, por consequência, sobre a tomada de decisão nas esferas políticas, inclusive sobre a necessidade de restrições sanitárias em decorrência de surtos. Nesse sentido, se é mais difícil promover a conscientização de toda uma coletividade, um conjunto de restrições que recaiam sobre instituições e seus líderes pode ter maior eficiência, resguardando, assim, os direitos de toda a sociedade.

A liberdade de crença não permite ao Estado suprimir da religião sua função primordial de oferecer respostas e propor reflexões sobre a vida humana, mas a partir do momento em que passa a promover ideias prejudiciais à população em geral, como a negação da gravidade do vírus ou a venda de curas milagrosas, surge um problema real e de difícil resolução, o qual, embora correlato, também não é o objeto do presente trabalho. Trata-se aqui exclusivamente da possibilidade de opor às instituições religiosas, de qualquer que seja a religião, regras sanitárias que incluem o fechamento total dos templos e proibição de eventos que importem na aglomeração de pessoas. Assim, independentemente de acreditarem ou não nas regras estabelecidas por especialistas da saúde, trata-se de definir se essas instituições devem seguir as mesmas regras igualmente impostas a estabelecimentos seculares como escolas, cinemas e bibliotecas. 


\section{A LIBERDADE RELIGIOSA E A LIBERDADE DE CULTO}

A controvérsia discutida na já citada ADPF nº 811/DF não é inédita na história ocidental, que, durante a gripe espanhola no século XX, viu um bispo de Zamora, na Espanha, conclamar procissões e cultos, elevando a mortalidade pela doença para um nível quatorze vezes maior do que a de cidades do mesmo país que seguiram as recomendações médicas (VEIGA, 2021). Porém, qualquer discussão aprofundada acerca da liberdade religiosa deve enfrentar complexas questões que se estendem por séculos.

Desde as primeiras sociedades humanas, formadas na era pré-cristã, havia uma “íntima relação entre o poder político e a função religiosa” (MACHADO, 1996, p. 14), algo que se verificou posteriormente em diversas civilizações, com destaque para a forte influência da Igreja Católica sobre os impérios português e espanhol, cujas colônias foram fundadas sobre essa mesma base. Com o tempo, muitos elementos de tradições religiosas majoritárias são incorporados como elementos culturais, como é o próprio calendário e suas datas comemorativas.

Por outro lado, o fato religioso se apresenta com uma especificidade única, pois diz respeito ao mesmo tempo à escolha de uma crença, a um conjunto de comportamentos éticos, à adesão a uma comunidade, e em algumas delas assume caráter missionário, implicando atividade proselitista (RIVERO; MOUTOUH, 2006, p. 523-524). Tudo isso leva à conclusão de que a religião não é um mero detalhe na vida das pessoas, e que o Estado laico deve respeitar todas as religiões e propiciar um ambiente onde todas possam conviver, e os fiéis tenham autonomia para professar sua fé.

É compreensível que muitas pessoas tenham se sentido lesadas pelo Estado quando foram impedidas de organizar e frequentar cultos religiosos, principalmente quando não há uma política pública ostensiva para informar aos cidadãos sobre a gravidade da Covid-19, agravado pelas campanhas de desinformação. Contudo, as políticas sanitárias de prevenção à doença não recaíram com tanta gravidade somente sobre as religiões, mas sobre setores inteiros da cultura e da economia. Em nome da saúde, milhões de pessoas foram obrigadas a se recolherem às suas residências, impedidas de trabalhar e de realizar atividades em locais públicos. Muitos inclusive tiveram a renda familiar comprometida, o que obrigou os governos a conceder auxílios financeiros. 
Foi exatamente a urgência em proteger a saúde da população e a necessária isonomia em relação a cada religião, e aos que não possuem nenhuma, que embasaram a decisão do Plenário do STF no julgamento da ADPF nº 811/DF. É pela situação completamente atípica que se justificaram inúmeras medidas drásticas que restringiram direitos da população, e, diante do quadro grave já vivido pelo Brasil no ano de 2021, não parece nada absurda a hipótese de fechamento total e temporário dos templos e a proibição de qualquer evento coletivo, mesmo reconhecendo-se a especial proteção à liberdade religiosa.

O Ministro Nunes Marques tem razão ao ressaltar que o serviço religioso não pode ser tratado como algo supérfluo (STF, 2021-C, p. 9), e que tem especial significado na vida dos fiéis, mas não considera dois importantes elementos: a pandemia é um fenômeno que atinge a todas as pessoas, independentemente de sua crença, exigindo esforço de toda a coletividade para conter o seu contágio; e que o fenômeno religioso não se restringe somente ao exercício do culto, de forma que a sua proibição temporária não afeta o núcleo do direito que é a crença.

O Ministro Gilmar Mendes abordou essas duas questões em seu voto na ADPF $\mathrm{n}^{\circ}$ 811/DF:

[...] A liberdade de credo deve ser assegurada de modo igual a todos, desde os membros de pequenas comunidades religiosas aos das grandes igrejas e de seitas exóticas ao círculo cultural.

Aqui é importante que se diga: a Constituição Federal de 1988 não alberga tão somente a proteção da fé cristã.

Na presente ADPF, a dimensão do direito à liberdade religiosa que reclama proteção jurídica afasta-se do núcleo de liberdade de consciência e mais tem a ver com a proteção constitucionalmente conferida à liberdade do exercício de cultos em coletividade.

Nesse aspecto, a doutrina estrangeira recorrentemente parte de uma interpretação do supracitado art. $9^{\circ}$ da Convenção Europeia de Direitos Humanos para assentar uma subclassificação das dimensões do direito fundamental à liberdade religiosa. (STF, 2021-B, p. 23).

Dessa forma, não há qualquer tipo de ameaça à dimensão interna da liberdade religiosa, o que talvez seja o único direito que não encontra restrições. Por outro lado, quanto à sua dimensão externa, somente no que toca aos atos que provoquem a aglomeração de pessoas, surge uma possibilidade bem definida de restrição, considerando que o seu exercício 
colocaria em risco direitos de toda a sociedade, inclusive daqueles que professam outra crença ou nenhuma.

Não há, nessa hipótese, uma subvalorização da liberdade religiosa ou mesmo da liberdade de culto, mas tão somente uma limitação interna do próprio direito, de acordo com a concepção de Dworkin (1999). Com efeito, seria inadmissível no Brasil uma nova religião que realizasse cerimônias com sacrifício humano, pois atentaria contra o inviolável direito à vida de terceiros, insculpido no art. 5º caput, da Constituição Federal (BRASIL,1988). Tratam-se de limites internos da liberdade religiosa, que em todos os demais aspectos permanece incólume.

Por outro lado, nenhuma restrição pode ser imposta sem que haja uma adequada justificativa. Em um cenário pandêmico, o que deve balizar qualquer restrição devem ser orientações técnicas de profissionais da saúde, baseadas em evidências científicas, como manifestou-se a maioria dos ministros do Supremo Tribunal Federal (STF, 2021-B, p. 46-47).

Com efeito, o Brasil encerrou o mês de setembro de 2021 com uma média diária de mortes por Covid-19 de 536, um número muito inferior a 3000 do pior período até hoje registrado (BRASIL, 2021). Ainda é um número muito alto que exige a atenção do Estado, sobretudo porque a pandemia ainda não tem previsão para acabar. Por outro lado, o Brasil hoje conta com um recurso muito importante para conter o vírus: as vacinas. Embora as vacinas hoje disponíveis não tenham total eficácia de impedir que uma pessoa contraia e transmita o SARS-CoV-2, elas reduzem substancialmente a taxa de transmissão, mesmo após a aplicação de uma única dose (HARIS, 2021).

Com o que se sabe hoje sobre o vírus e sobre as novas variantes, outras medidas podem ter prioridade sobre a suspensão total de cultos religiosos, como a exigência de apresentação de comprovante de vacinação por todos os fiéis, ou mesmo a permissão de eventos somente em locais com boa ventilação, respeitados também todos os outros protocolos de prevenção. No entanto, caso surja uma outra nova variante que se demonstre ainda mais eficaz no contágio, nada obsta que os cultos religiosos voltem a ser fechados compulsoriamente, desde que justificado por evidências científicas.

O Estado laico importa em uma separação entre igreja e Estado, porém, como coloca o art. 19, I, da Constituição Federal (BRASIL, 1988), essa vedação não proíbe a colaboração de interesse público. Dessa forma, antes de disputarem espaços de influência, é preciso mais do que nunca que haja cooperação entre o Estado e todas as instituições religiosas, de forma 
equânime, um esforço em prol de uma colaboração para controle da pandemia, principalmente para informar a sociedade de forma adequada, algo tão crucial para o sucesso da política de saúde pública. Contudo, caso a cooperação não seja possível, cabe ao Estado proteger em primeiro lugar o direito da coletividade à vida.

\section{CONCLUSÃO}

A pandemia de Covid-19 significou uma grande ruptura para a civilização humana, transformando rapidamente as relações sociais e impondo uma série de desafios para a sociedade civil e para o Estado. O mundo interconectado do século XXI possibilitou a rápida disseminação do SARS-CoV-2 para todos os continentes, mas também permitiu uma inédita cooperação entre a comunidade científica global, reunindo informações essenciais para a prevenção da doença, e posteriormente para o desenvolvimento de vacinas.

Por outro lado, as avançadas tecnologias da informação foram utilizadas para disseminar desinformação de todo tipo para atender a interesses políticos e econômicos de grupos mal intencionados. $\mathrm{O}$ acesso à informação adequada é a principal ferramenta de controle de doenças infecciosas, pois sem a colaboração da população, torna-se impossível contê-las. Nesse aspecto, o papel das instituições religiosas é de grande importância, pois além de observar as normas sanitárias para o desenvolvimento de suas atividades, também são importantes formadoras de opinião entre seus fiéis.

Embora em um cenário ideal devesse haver uma cooperação entre o Estado e as distintas religiões para permitir uma ação coordenada de controle de surtos pandêmicos, não é o que tem se verificado na prática, de forma que instituições religiosas e instituições seculares têm disputado espaço de influência sobre a sociedade. Assim, cabe ao Estado, como função precípua, proteger os direitos básicos de seus cidadãos, podendo inclusive promover temporariamente o fechamento total de templos religiosos e proibir atividades religiosas que desrespeitem as normas sanitárias de prevenção a doenças contagiosas, desde que justificado por normas técnicas e evidências científicas.

Uma vez que se tratam de restrições excepcionais e temporárias, tais medidas não violam a dimensão interna da liberdade religiosa, que se refere à liberdade de crença, mas tão somente restringem em parte a sua dimensão externa, de manifestação pública dessa crença. Com efeito, o indivíduo não perde a possibilidade de manifestar sua fé pelo uso de símbolos e 
ações individuais, ou mesmo atividades coletivas por meios não presenciais. Assim, tem-se por justificada a medida adotada por muitos entes estatais e referendada pelo Plenário do Supremo Tribunal Federal quando do julgamento da ADPF nº 811/DF. Até que novas técnicas de controle não tenham sido desenvolvidas, a restrição da liberdade de culto é uma medida justificada quando se trata de proteger o direito à vida dos próprios fiéis e do restante da sociedade.

Em um mundo extremamente conectado, a humanidade ainda deve enfrentar novos surtos de doenças infecciosas, com grande possibilidade de se tornarem pandemias. Com o aprendizado obtido a partir dessa experiência trágica, as instituições tanto seculares quanto religiosas devem estar mais bem preparadas para lidar com esses surtos no futuro, de forma a possibilitar uma melhor prevenção. É possível que os órgãos de vigilância sanitária dos diversos países estejam mais preparados para conter os surtos antes que se espalhem pelo mundo, e que as normas de construção de espaços públicos passem a exigir sistemas de ventilação mais eficientes, ajudando a prevenir até mesmo doenças com as quais convivemos há muito tempo, como a influenza. Porém, enquanto esta realidade não for verificada, será necessário que o Estado tome medidas enérgicas para proteger a saúde pública.

\section{REFERÊNCIAS}

BICKER, Laura. 'Exemplo' na luta contra covid-19, Coreia do Sul está à beira de 'surto nacional'. BBC News. Seul: 25 de ago. de 2020. Disponível em:

https://www.bbc.com/portuguese/internacional-53890469. Acesso em: 26 de set. de 2021.

BRASIL. Constituição da República Federativa do Brasil: texto constitucional promulgado em 5 de outubro de 1988, compilado até a Emenda Constitucional n 109/2021. Brasília: Senado Federal, 2021.

BRASIL. Supremo Tribunal Federal. Ação Direta de Inconstitucionalidade no 6341, Distrito Federal. Relator Ministro Marco Aurélio. Tribunal Pleno. Julgado em 15 de abr. de 2020. DJe de 13 de nov. de 2021. Disponível em:

https://jurisprudencia.stf.jus.br/pages/search/sjur436466/false. Acesso em 25 de set. de 2021. 2021-A.

BRASIL. Supremo Tribunal Federal. Ação de Descumprimento de Preceito Fundamental $n^{\circ}$ 811, São Paulo. Relator Ministro Gilmar Mendes. Tribunal Pleno. Julgado em 08 de abr. de 2021. DJe de 25 de jun. de 2021. Disponível em:

https://redir.stf.jus.br/paginadorpub/paginador.jsp?docTP=TP\&docID=756267154. Acesso em 26 de set. de 2021. 2021-B. 
BRASIL. Supremo Tribunal Federal. Ação de Descumprimento de Preceito Fundamental $n^{\circ}$ 701, Minas Gerais. Relator Ministro Nunes Marques. Decisão Monocrática, 03 de abr. de 2021. DJe de 05 de abr. de 2021. Disponível em:

http://portal.stf.jus.br/processos/downloadPeca.asp?id=15346073522\&ext=.pdf. Acesso em 26 de set. de 2021. 2021-C.

BRASIL. Ministério da Saúde. Covid-19 no Brasil. Óbitos novos por dia de notificação com Média Móvel de 14 dias. Brasília, 08 de abr. de 2021. Disponível em:

https://qsprod.saude.gov.br/extensions/covid-19_html/covid-19_html.html. Acesso em: 21 de set. de 2021-D.

CERQUEIRA-SILVA et. al. Influence of age on the effectiveness and duration of protection in Vaxzevria and CoronaVac vaccines. medRxiv, 27 de ago. de 2021. Disponível em: https://www.medrxiv.org/content/10.1101/2021.08.21.21261501v2.full.pdf+html. Acesso em: 27 de set. de 2021.

DWORKIN, Ronald. O Império do Direito. Trad. São Paulo: Martins Fontes, 1999.

EPIMED MONITOR. Uso de Suporte na Unidade e Principais Desfechos. Período: 01/03/2020 - 22/09/2021. Registro Nacional de Terapia Intensiva. Disponível em: http://www.utisbrasileiras.com.br/sari-covid-19/benchmarking-covid-19/\#!/sari-covid-19consolidado. Acesso em: 27 de set. de 2021.

FERNANDES, Mariana. Covid-19: culto em igreja nos EUA deixa 38\% dos fiéis contaminados. Correio Braziliense, 19 de maio de 2020. Disponível em: https://www.correiobraziliense.com.br/app/noticia/ciencia-esaude/2020/05/19/interna_ciencia_saude,856513/covid-19-culto-em-igreja-nos-eua-deixa-38dos-fieis-contaminados.shtml. Acesso em: 26 de set. de 2021.

HARIS, Ross J. et. al. Impact of vaccination on household transmission of SARS-COV-2 in England. Public Health England. Londres, 28 de abr. de 2021. Disponível em: https://khub.net/documents/135939561/390853656/Impact+of+vaccination+on+household+tr ansmission+of+SARS-COV-2+in+England.pdf/35bf4bb1-6ade-d3eb-a39e9c9b25a8122a?t=1619601878136. Acesso em: 29 de set. de 2021.

IAMARINO, Atila; LOPES, Sônia. Coronavírus: explorando a pandemia que mudou o mundo. 1. ed. São Paulo: Moderna, 2020.

MACHADO, Jónatas Eduardo Mendes. Liberdade Religiosa Numa Comunidade Constitucional Inclusiva. Coimbra: Coimbra Editora, 1996.

MARQUÉS, Nestor F. Fake news de la antigua Roma: Engaños, propaganda y metiras de hace 2000 años. Madrid: Espasa, 2019.

OUR WORLD IN DATA. Cumulative confirmed COVID-19 deaths. 26 de set. de 2021. Disponível em: https://ourworldindata.org/covid-deaths. Acesso em: 26 de set. de 2021. 
PRUDENCIANO, Gregory. Brasil tem mais de 6.300 pessoas na fila por leitos de UTI Covid. CNN Brasil. São Paulo, 25 mar 2021. Disponível em:

https://www.cnnbrasil.com.br/saude/2021/03/26/brasil-tem-mais-de-6300-pessoas-na-fila-porleitos-de-uti. Acesso em 26 de set. de 2021.

RIVERO, Jean; MOUTOUH, Hugues. Liberdades Públicas. São Paulo: Martins Fontes, 2006.

SOARES, Ana Angélica; FERREIRA, Simone. Hospitais de campanha e a expansão da capacidade de atendimento no enfrentamento à COVID-19. Observatório de Política e Gestão Hospitalar. 7 de dez. de 2020. Disponível em:

https://observatoriohospitalar.fiocruz.br/debates-e-opinioes/hospitais-de-campanha-eexpansao-da-capacidade-de-atendimento-no-enfrentamento. Acesso em: 27 de set. de 2021.

SCHWARCZ, Lilia Moritz; STARLING, Heloísa Murgel. A Bailarina da Morte: A Gripe Espanhola no Brasil. São Paulo: Companhia das Letras, 2020.

TA-CHOU, Ng. Comparison of Estimated Effectiveness of Case-Based and Population-Based Interventions on COVID-19 Containment in Taiwan. JAMA Internal Medicine, $1^{\circ}$ de jul. de 2021; 181(7): p. 913-921.

UCHOA, Pablo. Coronavírus: por que alguns países são mais eficientes que outros na luta contra a covid-19. BBC News Brasil, 18 de jan. de 2021. Disponível em:

https://www.bbc.com/portuguese/geral-55704511. Acesso em: 26 de set. de 2021.

VEIGA, Edison. Como bispo que insistiu em missas virou símbolo de alta de mortes na gripe espanhola. BBC News Brasil, Blend, 06 de abr. de 2021. Disponível em:

https://www.bbc.com/portuguese/geral-56647695. Acesso em 27 de set. de 2021.

WALLACE, Arturo. Coronavírus: como foram controladas as epidemias de Sars e Mers (e no que elas se diferenciam da atual). BBC News Mundo, 30 de mai. de 2020. Disponível em: https://www.bbc.com/portuguese/internacional-52815216. Acesso em: 26 de set. de 2021. 